\title{
Does Stone Entrapment With "Uro-Net" Improve Ho:YAG Laser Lithotripsy Efficiency in Percutaneous Nephrolithotomy and Cystolithopaxy?: an In Vitro Study
}

\author{
Giovanni Scala Marchini, Aayushi Rai, Shubha De, Carl Sarkissian, Manoj Monga \\ Glickman Urological and Kidney Institute, Cleveland Clinic Foundation, Cleveland, OH, USA
}

\section{ABSTRACT}

Purpose: to test the effect of stone entrapment on laser lithotripsy efficiency.

Materials and Methods: Spherical stone phantoms were created using the BegoStone ${ }^{\circledR}$ plaster. Lithotripsy of one stone (1.0g) per test jar was performed with Ho:YAG laser (365 $\mathrm{um}$ fiber; 1 minute/trial). Four laser settings were tested: I-0.8J,8Hz; II-0.2J,50Hz; III-0.5J,50Hz; IV-1.5J,40Hz. Uro-Net (US Endoscopy) deployment was used in 3/9 trials. Post-treatment, stone fragments were strained though a $1 \mathrm{~mm}$ sieve; after a 7-day drying period fragments and unfragmented stone were weighed. Uro-Net nylon mesh and wire frame resistance were tested (laser fired for 30s). All nets used were evaluated for functionality and strength (compared to 10 new nets). Student's T test was used to compare the studied parameters; significance was set at $\mathrm{p}<0.05$.

Results: Laser settings I and II caused less damage to the net overall; the mesh and wire frame had worst injuries with setting IV; setting III had an intermediate outcome; 42\% of nets were rendered unusable and excluded from strength analysis. There was no difference in mean strength between used functional nets and non-used devices (8.05 vs. $7.45 \mathrm{lbs}$, respectively; $\mathrm{p}=0.14)$. Setting IV was the most efficient for lithotripsy $(1.9 \pm$ $0.6 \mathrm{mg} / \mathrm{s} ; \mathrm{p}<0.001$ ) with or without net stabilization; setting III was superior to I and II only if a net was not used.

Conclusions: Laser lithotripsy is not optimized by stone entrapment with a net retrieval device which may be damaged by high energy laser settings.

\section{ARTICLE INFO}

\section{Key words:}

Lithotripsy, Laser; Nephrostomy, Percutaneous;

Calculi

Int Braz J Urol. 2013; 39: 579-86

Submitted for publication: December 10, 2012

Accepted after revision: July 02, 2013

\section{INTRODUCTION}

With advances in endoscopic technology, the treatment of urinary calculi has dramatically shifted from the traditional open surgical procedures to minimally invasive approaches that often require intracorporeal lithotripsy. Urinary stone fragmentation may be achieved by ballistic, ultrasonic, electrohydraulic or laser devices (1). The best surgical technique and energy source to be applied differs according to stone and patient characteristics. The ability to fragment any stone composition allied to a secure profile for the urinary tract and development of small fibers suitable for flexible endoscopy led the Holmium:Yttrium-Aluminum-Garnet Laser (Ho:YAG) to become the preferred energy source for stone breakdown during ureteroscopy (URS) (2-5). In contrast, intracorporeal lithotripsy during percutaneous nephrolithotomy (PCNL) and cystolithopaxy (CYS) is usually performed by ultrasonic or pneumatic devices as fragmentation and extraction can be performed with greater efficiency (6-8). Percutaneous applications of laser lithotripsy are usually 
reserved to treat branched or difficult to access stones with the flexible nephroscope.

We hypothesized that stabilization of calculi in the larger confines of the bladder or kidney could facilitate the efficiency of percutaneous intracorporeal laser lithotripsy, expanding the role of the holmium laser for this application. The purpose of our study was to test the efficiency of laser lithotripsy with and without stabilization of the stone with an entrapment device.

\section{MATERIALS AND METHODS}

\section{Stone Model}

Stone phantoms were created using the BegoStone $^{\circledR}$ (BEGO USA, Smithfield, RI) plaster, which has acoustic and mechanical properties similar to hard kidney stones composed of calcium oxalate monohydrate (CaOMH) and brushite (final hardness $=302 \mathrm{~N} / \mathrm{mm}^{2}$ ). BegoStone ${ }^{\circledR}$ was used to create spherical stone phantoms using a plastic spherical mold. A mixture of BegoStone ${ }^{\circledR}$ with water was prepared at room temperature $\left(20^{\circ} \mathrm{C}\right)$, using a 10:2 powder/water mixing ratio (10 $\mathrm{g}$ of BegoStone ${ }^{\circledR}$ powder mixed with $2 \mathrm{~mL}$ of water). Stones with visible fractures were excluded. The stones were measured for consistency in weight and diameter: mean baseline stone weight was $1.07 \pm 0.01 \mathrm{~g}$; mean baseline stone diameter was $1.0 \pm 0.1 \mathrm{~cm}$. Nine stone phantoms per laser setting were prepared.

\section{Net Characteristics, Laser Settings, and Experi- mental Setup}

The experiment was conducted using polypropylene style line jars (4oz-58 mm Olcott Plastics Inc.; 2.55 inches high, 2.11 inches diameter, $4 \mathrm{oz}$ volumetric capacity) in which one stone was used per trial. The jar was covered with a transparent polythene coat to provide a fulcrum point for a 30 F Amplatz sheath which was inserted perpendicular through the cover (Figure-1). A rigid nephroscope (26 F Karl Storz) was utilized to access the stone through the Amplatz sheath. A 365um laser fiber (LEONI Fiber Optics Inc.) attached to a holmium laser generator (Power Suite $100 \mathrm{~W}$; LUMENIS) was introduced through the nephroscope working channel while stabilized inside a $5 \mathrm{Fr}$ open-ended ureteral catheter and placed in direct contact with the calculus under direct endoscopic vision. The laser fiber was inspected after each trial and replaced with a new fiber if any burnback of the tip was noted.

Before lithotripsy each dry stone phantom mass was measured to assure a total stone burden of approximately $1.07 \mathrm{~g}$ per recipient. Laser lithotripsy was performed with continuous normal saline irrigation through the irrigation port of the rigid nephroscope with gravity pressure of $20 \mathrm{~cm}$ $\mathrm{H}_{2} \mathrm{O}$. The trial laser time period was set at one minute per stone. Four laser settings with increasing energy were tested: I $-0.8 \mathrm{~J}$ and $8 \mathrm{~Hz}(6.4 \mathrm{~W})$; II $-0.2 \mathrm{~J}$ and $50 \mathrm{~Hz}(10 \mathrm{~W})$; III $-0.5 \mathrm{~J}$ and $50 \mathrm{~Hz}$ $(25 \mathrm{~W})$; IV $-1.5 \mathrm{~J}$ and $40 \mathrm{~Hz}(60 \mathrm{~W})$. A total of nine stone trials per laser setting were performed: 3 with and 6 without net deployment. During the trials, if the calculus migrated off the tip of the laser fiber, firing was suspended, the nephroscope was maneuvered until contact between the stone and the laser tip was restored, and firing resumed.

A 5.4 F Uro-Net retriever (US Endoscopy Model 00913604, Mentor OH) was used through the working channel of the nephroscope for stone entrapment. The device consists of a $3.0 \mathrm{~cm}$ wide, 1.25 $\mathrm{cm}$ long, and 1-mm open spacing nylon mesh pouch with a single loop nitinol wire frame (Figure-1).

The susceptibility of the Uro-Net to be damage by the holmium laser was tested in a saline environment. First, the laser was fired continuously for 30 seconds while in direct contact with the nylon net. Second, the laser was fired directly onto the wire frame until the nitinol wire broke. All trials using the net were performed with new devices.

Post-laser treatment, the stone fragments from each test jar were strained though a $1 \mathrm{~mm}$ sieve. The fragments that filtered through were discarded and the residual fragments were set aside for a 7-day drying period. At the end of this period, the fragments and the unfragmented stone were weighed, the difference in weight from baseline were calculated. Size cutoff of $1 \mathrm{~mm}$ was established because fragments smaller than $1 \mathrm{~mm}$ have little clinical significance. The mean weight loss of the stone fragments and the weight loss per unit of time were calculated to evaluate fragmentation efficiency of each particular laser setting. 
Figure 1 - Schematic view of Ho:YAG laser lithotripsy with the Uro-Net stone entrapment device during percutaneous nephrolithotomy and cystolithopaxy.

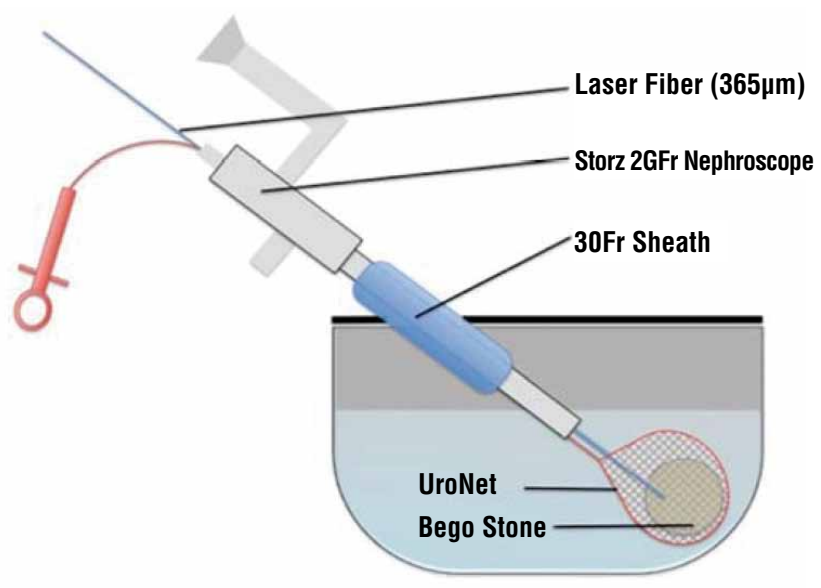

Nets used during lithotripsy process were evaluated for damage. They were inspected for integrity of the wire frame and net mesh. Defects in the mesh were characterized as small $(<2.5 \mathrm{~mm})$, medium $(2.5-5.0 \mathrm{~mm})$ or large $(>5 \mathrm{~mm})$. The functionality and strength of the devices were tested by placing a $6 \mathrm{~mm}$ artificial metallic bead in the net and applying a force to the handle (Wagner FDIX 10x.05 lbf Force Gage, USE-236, Calibration Due 9/11/2013) until the net failed or handle reached its maximum excursion (Figure-2). A fixture (811003) was used with the force gauge to pull the handle and measure the peak force in pounds (lbs).
Ten new nets (US Endoscopy Model 00913604, Mentor $\mathrm{OH}$, stock lot number 64188) that had not undergone any lithotripsy process were also tested in the same method for comparison. Devices with broken loops or larger holes could not be included in net strength analysis.

\section{Statistical analysis}

Statistical analysis was performed using SPSS ${ }^{\circledR}$ version 20 (SPSS, Inc., Chicago, IL, USA). Results were expressed as mean \pm standard deviation. Paired Student's t test was used to compare pre and post-treatment stone weight. Independent Sample T Test was used to compare differences in mean weight changes between net and no net trials within each laser setting and to compare net strength between used and new nets. Two-tailed values of $\mathrm{p}<$ 0.05 were considered statistically significant.

\section{RESULTS}

Impact of laser on Net-Mesh and Wire-frame

Evaluation of new nets that underwent direct firing of the laser on the wire and mesh demonstrated that the two laser settings with lower energy (I and II) did not alter mesh integrity and the mean time for wire collapse was 7 seconds for setting I and 5 seconds for setting II. The higher energy setting (IV) caused visible damage to the mesh in $50 \%$ of the trials and required only 3 seconds for wire breakdown. The third setting had an intermediate outcome;

Figure 2 - Net strength testing with a force gauge handle (A) by holding a $6 \mathrm{~mm}$ artificial metallic bead (B) and applying a force to the handle until the net failed or handle reached its maximum excursion.

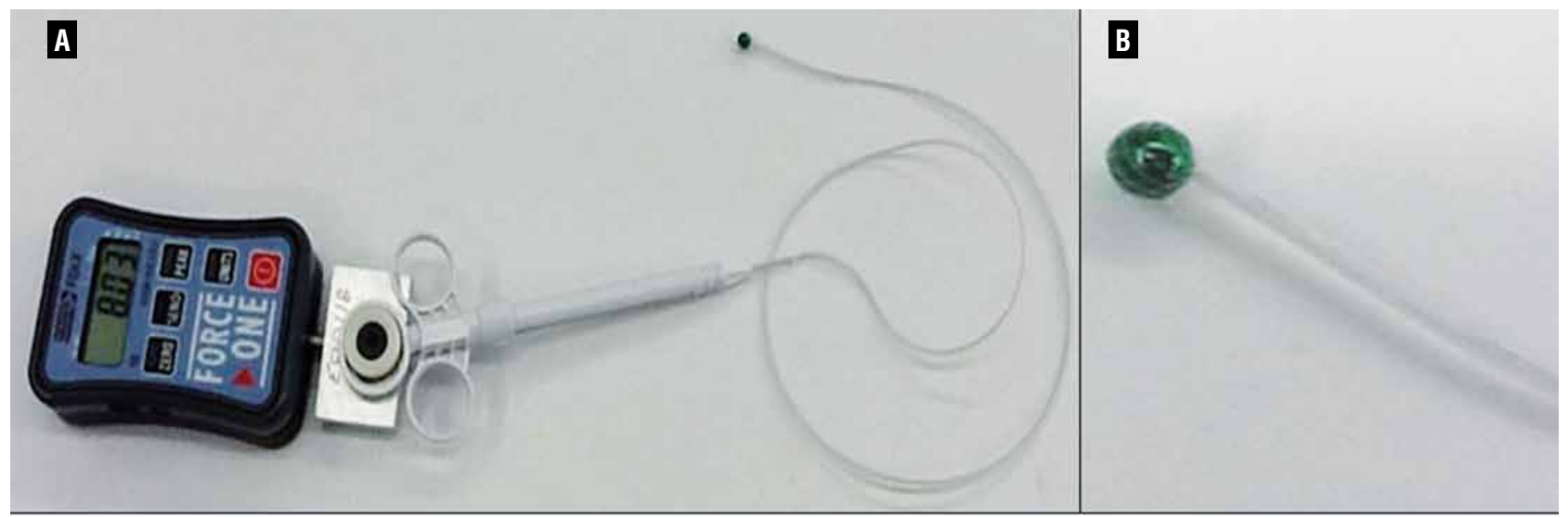


it damaged the mesh in 50\% of the trials but took 5 seconds to break the wire. Net strength was not tested in any of these devices due to wire frame breakage.

Evaluations of nets that underwent laser lithotripsy of calculi demonstrated that settings I and II resulted in only small (33\% of nets) or medium (67\% of nets) tears in the net. Neither setting impacted the integrity of the wire frame and all nets remained functional despite these small mesh tears. With setting III, a large opening was seen in $67 \%$ of meshs but no wire damage occurred. Setting IV, on the contrary, imposed large breaches in all nets tested and broke the wire frame in 33\% of trials. In all, 42\% of nets undergoing lithotripsy were rendered unusable and excluded from the strength analysis because of a broken wire frame or large mesh defect.

In the remaining devices, net strength testing demonstrated that the overall net strength was $8.05 \pm 0.29(7.67-8.59)$ lbs. The same test was performed on ten new devices where all of the nets also stretched until the handle reached its maximum excursion with a mean force of $7.45 \pm$ 1.16 (4.68 - 8.54) lbs. We found no difference in mean strength between used nets that maintained their functionality and non-used nets $(\mathrm{p}=0.14)$.
Stone Weight Analysis and Fragmentation Efficacy

Mean time to capture the stone with the net varied from 1 to 5 seconds. Stone fragments that broke off from the test stone were analyzed. Stone fragments with settings I and II were small, with no significant $>1 \mathrm{~mm}$ stone fragments in any of the trials. Settings III and IV resulted in larger stone fragments (>1 mm) in $44 \%$ of trials for each setting ( 5 fragments in setting III and 13 in IV).

Mean overall post-laser stone weight was significantly lower than baseline for all laser settings $(\mathrm{p}<0.001)$. At power setting I, mean post-laser stone weight was significantly lower than baseline only on trials without the net ( $p=0.003$ vs. $p=0.14$, respectively). When comparing net stabilization to no net trials, there was no statistically significant difference in absolute $(p=$ $0.17)$ and relative weight loss $(p=0.15)$ (Table-1; Figure-3).

At power settings II and III, mean post-laser stone weight was also significantly lower than baseline only on trials without the net $(\mathrm{p}$ $=0.01$ vs. $p=0.17$; and $p<0.001$ vs. $p=0.06$, respectively). At both settings, mean absolute and relative weight loss were similar on trials with and without the net $(p>0.05)$.

Table 1 - Comparison of absolute and relative weight change between net and no net trials within each laser setting.

\begin{tabular}{lcccc}
\hline Laser Setting & I & II & III & IV \\
\hline (Energy / Frequency) & $(0.8 \mathrm{~J} / 8 \mathrm{~Hz})$ & $(0.2 \mathrm{~J} / 50 \mathrm{~Hz})$ & $(0.5 \mathrm{~J} / 50 \mathrm{~Hz})$ & $(1.5 \mathrm{~J} / 40 \mathrm{~Hz})$ \\
Absolute Weight Change $(\mathbf{g})$ & & & \\
$\quad$ Net Trials $(\mathrm{n}=3)$ & $0.0073 \pm 0.005$ & $0.0073 \pm 0.006$ & $0.0477 \pm 0.022$ & $0.1077 \pm 0.033$ \\
No Net Trials $(\mathrm{n}=6)$ & $0.0135 \pm 0.031$ & $0.0205 \pm 0.018$ & $0.0582 \pm 0.015$ & $0.1210 \pm 0.037$ \\
Significance $(\mathrm{p})^{*}$ & 0.17 & 0.25 & 0.51 & 0.61 \\
Relative Weight Change (\%) & & & & \\
Net Trials $(\mathrm{n}=3)$ & $0.67 \pm 0.50$ & $0.68 \pm 0.56$ & $4.84 \pm 2.20$ & $10.41 \pm 3.13$ \\
No Net Trials $(\mathrm{n}=6)$ & $1.28 \pm 0.28$ & $1.95 \pm 1.75$ & $5.80 \pm 1.54$ & $11.56 \pm 3.64$ \\
Significance $(p)^{*}$ & 0.15 & 0.24 & 0.25 & 0.64
\end{tabular}

* Independent Sample T Test 
Figure 3 - Relative weight difference for each laser setting considering overall performance and separate trials with and without the stone entrapment device.

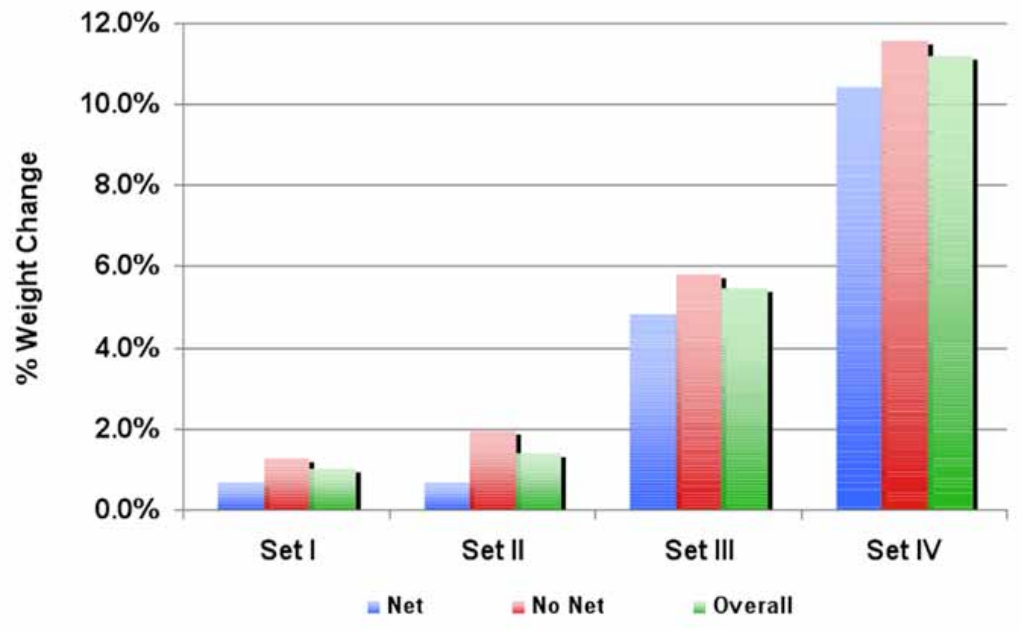

At power setting IV, significant differences in stone weight from baseline were seen both with the net $(p=0.03)$ and without the net $(p<0.001)$. Mean absolute and relative weight loss were similar in trials with and without the net $(\mathrm{p}=0.61$ and $\mathrm{p}$ $=0.64)$.

\section{Stone Entrapment Influence on Fragmentation Efficiency}

Overall, laser setting I resulted in a mean weight decrease of $0.2 \pm 0.1 \mathrm{mg}$ per second of lithotripsy $(0.1 \mathrm{mg} / \mathrm{sec}$ with net; $0.2 \mathrm{mg} / \mathrm{sec}$ without the net) (Figure-4). Compared to setting I, laser setting II had a similar lithotripsy efficiency ( $p>0.05)$ with a mean weight decrease of $0.2 \pm 0.3 \mathrm{mg} / \mathrm{sec}$ ( $0.1 \mathrm{mg} / \mathrm{sec}$ with net; $0.3 \mathrm{mg} / \mathrm{sec}$ without the net). Setting III had a better overall lithotripsy efficiency than settings I and II $(0.9 \pm 0.3 \mathrm{mg} / \mathrm{sec} ; \mathrm{p}<0.01)$. Although this superiority was seen on trials without the net $(1 \mathrm{mg} / \mathrm{sec} ; \mathrm{p}<0.01)$ it was not reproduced on net trials $(0.8 \mathrm{mg} / \mathrm{sec} ; \mathrm{p}>0.05)$. Laser setting IV resulted in a mean overall weight decrease of $1.9 \pm$ $0.6 \mathrm{mg} / \mathrm{sec}$ and outperformed all other settings in terms of fragmentation efficiency $(p<0.01)$; setting IV had the best performance with $(1.8 \mathrm{mg} / \mathrm{sec})$ or without $(2.0 \mathrm{mg} / \mathrm{sec})$ net stabilization $(\mathrm{p}<0.001)$.

\section{DISCUSSION}

The Ho:YAG laser lithotripsy mechanism is photothermal (9). It is an important tool in the urologist armamentarium to treat stones in any location and is considered the gold-standard energy modality during ureterolithotripsy (10-12). Ho:YAG laser has potential applicability in CYS and PCNL for the management of complex bladder and kidney calculi. One challenge during intracorporeal lithotripsy in the kidney or bladder is stabilization of the calculus. The objective of our study was to evaluate the impact of stone entrapment on fragmentation efficiency in a model representative of the bladder and kidney.

We found a significant decrease in mean stone weight due to laser lithotripsy with all laser settings irrespective of calculi entrapment, which supports the observation that the Ho:YAG laser is effective even when treating hard stones. We also observed larger fragments for settings with higher power, i.e., settings III (25W) and IV (60W). Fragments $>1 \mathrm{~mm}$ were obtained during $44 \%$ of trials for these high-energy settings compared to none with the low-energy settings I (6.4W) and II (10W). The fragment size has relevance in terms of the 
Figure 4 - Influence of laser settings and entrapment device on fragmentation efficiency characterized by absolute weight reduction per second of lithotripsy.

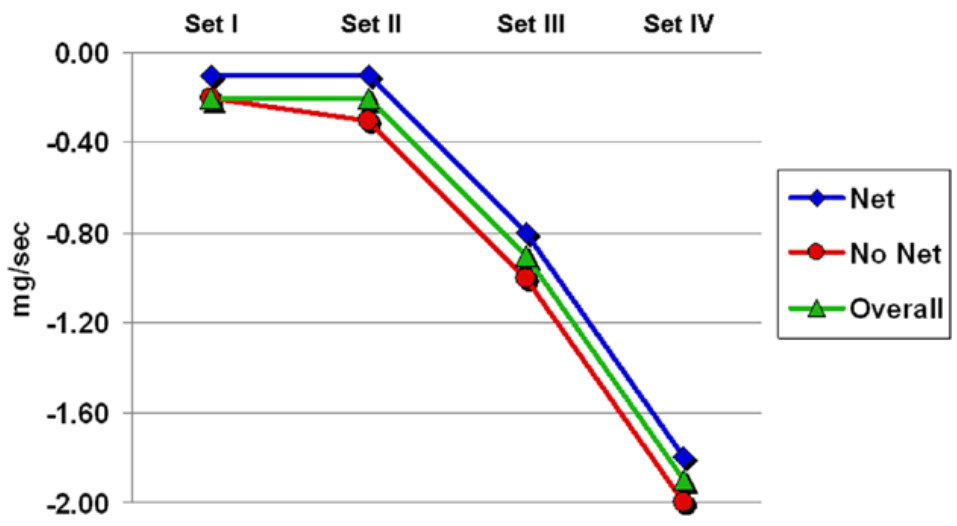

extra time and cost that may be incurred to basket and remove these larger fragments. When extrapolating the in vitro positive correlation between laser energy and stone fragmentation efficiency to the in vivo setting, factors as stone retropulsion, migration and safety to surrounding tissues must be taken into consideration. Fragmentation of urinary calculi is usually performed without entrapment by any specific retrieval mechanism. Stone breakdown during PCNL is typically performed with ultrasonic or pneumatic lithotripters while laser lithotripsy is typically reserved for stone fragments that cannot be reached with the rigid nephroscope. With any energy modality, fragment migration is not uncommon, however few entrapment devices have been developed to address that matter. One solution would be to fashion a tool capable of holding the stone for fragmentation. For that, the device should be sizeable and also resistant to the energy source being applied to the stone.

By using the net to hold the stone, we expected to achieve increased fragmentation efficiency due to annulment of stone retropulsion and migration effects. Instead, stone entrapment resulted in a decrease in fragmentation efficiency. It is possible that the lack of improvement in fragmentation efficiency with stone entrapment is due to the inability to effectively maneuver the laser fiber through the working channel shared with the entrapment device. This limitation would be simi- lar to that noted with laser baskets which allow the laser to fire only through the center of the stone. Development of better methods to optimize coupling between laser fiber and the entrapped stone deserves further consideration. A device that would allow capture of the stone independent of the working channel, leaving the operator with free movement of the laser fiber might result in different findings. Salimi et al. described a novel basket retrieval device with an inner channel for laser fiber deployment such that the stone could be pulverized and the fragments captured (13). The mesh of the basket is covered with a laser resistant material of polytetrafluoroethylene that can withstand the Ho:YAG laser energy, making it a durable stone retrieval option. Although promising, maneuverability of the laser fiber within the basket might also be restricted.

Stone burden is an important predictor of surgical time during CYS and for larger calculi the Ho:YAG laser outperform other devices $(14,15)$. Both transurethral and percutaneous approaches have been proved efficient for bladder stone management (16-18). Miller et al. tested stone extraction by percutaneous CYS using the EndoBag Entrapment sac (US Surgical, Norwalk, CT) in a prospective study comprising patients with augmented bladders (17). The Endobag was deployed through the canula of a $10 \mathrm{~mm}$ laparoscopic trocar and the stones maneuvered into the sac. The entrap- 
ment sac perforated in 1 of 4 cases due to disproportional sac and stone dimensions, which led the authors not to recommend its use when adjuvant lithotripsy is required. Lam et al. tested the same device and used ultrasonic lithotripsy in 8 patients with large calculi (mean size of $41 \mathrm{~mm}$ ) (18). All patients were rendered stone free after a single procedure and the device was considered safe.

We found the intermediate laser setting $(0.5 \mathrm{~J}, 50 \mathrm{~Hz})$ provided a good balance between achieving fragmentation efficiency and minimizing damage to the Uro-Net. However, overall fragmentation efficiency did not improve with net stabilization for this on any laser setting. The Uro-Net may play an important role during mini-PCNLs with laser lithotripsy where nephroscopes with smaller working channels do not accommodate certain ultrasonic probes. Also, the Uro-Net may still hold promise for stabilization for ultrasonic or pneumatic lithotripsy.

\section{CONCLUSIONS}

Fragmentation efficiency increases with higher laser energy settings. Laser lithotripsy is not optimized by stone entrapment with a net retrieval device and high laser energy settings can damage the net mesh and wire frame.

\section{ABBREVIATIONS}

$\mathrm{CaOMH}=$ Calcium Oxalate Monohydrate

CYS = Cystolithopaxy

Ho:YAG = Holmium:Yttrium-Aluminum-Garnet

Laser

LBS $=$ Pounds

PCNL = Percutaneous Nephrolithotomy

URS = Ureteroscopy

\section{CONFLICT OF INTEREST}

None declared.

\section{REFERENCES}

1. Preminger GM, Tiselius HG, Assimos DG, Alken P, Buck AC, Gallucci M, et al.: 2007 Guideline for the management of ureteral calculi. Eur Urol. 2007; 52: 1610-31.

2. Francesca F, Scattoni V, Nava L, Pompa P, Grasso M, Rigatti $P$ : Failures and complications of transurethral ureteroscopy in 297 cases: conventional rigid instruments vs. small calibersemirigid ureteroscopes. Eur Urol. 1995; 28: 112-5.

3. Yaycioglu 0, Guvel S, Kilinc F, Egilmez T, Ozkardes H: Results with $7.5 \mathrm{~F}$ versus $10 \mathrm{~F}$ rigid ureteroscopes in treatment of ureteral calculi. Urology. 2004; 64: 643-6; discussion 646-7.

4. Kalra P, Le NB, Bagley D: Effect of pulse width on object movement in vitro using holmium:YAG laser. J Endourol. 2007; 21: 228-31.

5. Lee H, Ryan RT, Teichman JM, Landman J, Clayman RV, Milner TE, et al:: Effect of lithotripsy on holmium:YAG optical beam profile. J Endourol. 2003; 17: 63-7.

6. Aboumarzouk OM, Kata SG, Keeley FX, McClinton S, Nabi G: Extracorporeal shock wave lithotripsy (ESWL) versus ureteroscopic management for ureteric calculi. Cochrane Database Syst Rev. 2012; 16: 5. CD006029.

7. Warmerdam GJ, De Laet K, Wijn RP, Wijn PF: Treatment options for active removal of renal stones. J Med Eng Technol. 2012; 36: 147-55.

8. Gücük A, Uyetürk U, Oztürk U, Kemahli E, Yildiz M, Metin A: Does the Hounsfield unit value determined by computed tomography predict the outcome of percutaneousnephrolithotomy? J Endourol. 2012; 26: 792-6.

9. Vassar GJ, Chan KF, Teichman JM, Glickman RD, Weintraub ST, Pfefer TJ, et al.: Holmium: YAG lithotripsy: photothermal mechanism. J Endourol. 1999; 13: 181-90.

10. Teichman JM, Vassar GJ, Bishoff JT, Bellman GC: Holmium:YAG lithotripsy yields smaller fragments than lithoclast, pulsed dye laser or electrohydraulic lithotripsy. J Urol. 1998; 159: 17-23.

11. Razvi HA, Denstedt JD, Chun SS, Sales JL: Intracorporeal lithotripsy with the holmium:YAG laser. J Urol. 1996; 156: 912-4.

12. Teichman JM, Rogenes VJ, Mclver BJ, Harris JM: Holmium:yttrium-aluminum-garnet laser cystolithotripsy of large bladder calculi. Urology. 1997; 50: 44-8.

13. Salimi N, Mahajan A, Don J, Schwartz B: A novel stone retrieval basket for more efficient lithotripsy procedures. J Med Eng Technol. 2009; 33: 142-50.

14. Kawahara T, Ito H, Terao H, Ogawa T, Uemura $\mathrm{H}$, Kubota $\mathrm{Y}$, et al.: Stone area and volume are correlated with operative time for cystolithotripsy for bladder calculi using a holmium: yttriumgarnet laser. Scand J Urol Nephrol. 2012; 46: 298-303. 
15. Un-no T, Nagata M, Takayama T, Mugiya S, Suzuki K, Fujita K: [Cystolithotripsy for bladder stones: comparison of holmium:YAG laser with Lithoclast as a lithotripsy device]. Hinyokika Kiyo. 2000; 46: 307-9.

16. Elbahnasy AM, Farhat YA, Aboramadan AR, Taha MR: Percutaneous cystolithotripsy using self-retaining laparoscopic trocar for management of large bladder stones. J Endourol. 2010; 24: $2037-41$.
17. Miller DC, Park JM: Percutaneous cystolithotomy using a laparoscopic entrapment sac. Urology. 2003; 62: 333-6; discussion 336 .

18. Lam PN, Te CC, Wong C, Kropp BP: Percutaneous cystolithotomy of large urinary-diversion calculi using a combination of laparoscopic and endourologictechniques. J Endourol. 2007; 21: $155-7$

Correspondence address:

Dr. Manoj Monga

Glickman Urological and Kidney Institute

Cleveland Clinic

Q10 9500 Euclid Avenue Cleveland, OH, 44195, USA

Fax: + 1216 445-8678

E-mail:mongam@ccf.org 